\title{
A novel polymorphism in the coding region of the vasopressin type 2 receptor gene
}

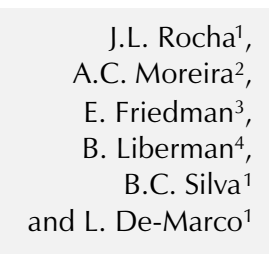

\section{Correspondence}

L. De-Marco

Departamento de Farmacologia Instituto de Ciências Biológicas

Universidade Federal de

Minas Gerais

Av. Antonio Carlos, 6627

31270-010 Belo Horizonte, MG

\section{Brasil}

Fax: 55 (031) 441-0835

E-mail: Idemarco@mono.icb.ufmg.br

Presented at the International Symposium "Neuroendocrine Control of Body Fluid Homeostasis", Ribeirão Preto, SP, Brasil, August 17-20, 1996.

Research supported by FAPEMIG, CNPq and CAPES. Publication supported by FAPESP.

Received November 29, 1996 Accepted January 6, 1997

\author{
${ }^{1}$ Departamento de Farmacologia, Universidade Federal de Minas Gerais, \\ 31270-010 Belo Horizonte, MG, Brasil \\ 2Departamento de Clínica Médica, Faculdade de Medicina de Ribeirão Preto, \\ Universidade de São Paulo, 14049-900 Ribeirão Preto, SP, Brasil \\ ${ }^{3}$ Department of Hematology and Genetics, Chaim Sheba Medical Center, \\ Tel-Hashomer 52621, Israel \\ ${ }^{4}$ Unidade de Endocrinologia, Hospital Brigadeiro, 01401-901 São Paulo, SP, Brasil
}

\begin{abstract}
Nephrogenic diabetes insipidus (NDI) is a rare disease characterized by renal inability to respond properly to arginine vasopressin due to mutations in the vasopressin type 2 receptor (V2(R)) gene in affected kindreds. In most kindreds thus far reported, the mode of inheritance follows an X chromosome-linked recessive pattern although autosomal-dominant and autosomal-recessive modes of inheritance have also been described. Studies demonstrating mutations in the V2(R) gene in affected kindreds that modify the receptor structure, resulting in a dys- or nonfunctional receptor have been described, but phenotypically indistinguishable NDI patients with a structurally normal V2(R) gene have also been reported. In the present study, we analyzed exon 3 of the $\mathrm{V} 2(\mathrm{R})$ gene in 20 unrelated individuals by direct sequencing. A $\mathrm{C} \rightarrow \mathrm{T}$ alteration in the third position of codon 331 $(\mathrm{AGC} \rightarrow \mathrm{AGT})$, which did not alter the encoded amino acid, was found in nine individuals, including two unrelated patients with NDI. Taken together, these observations emphasize the molecular heterogeneity of a phenotypically homogeneous syndrome.
\end{abstract}

Key words

- Vasopressin

- Receptor

- Polymorphism

- Diabetes insipidus

- Receptor gene polymorphism
Germline mutations in the vasopressin type 2 receptor (V2(R)) gene have been demonstrated to co-segregate with nephrogenic diabetes insipidus, a rare disorder characterized by the inability to concentrate the urine due to a renal insensitivity to vasopressin.

To our knowledge, only two neutral polymorphisms have been demonstrated in this receptor gene (1,2). In addition, an A61V mutation that does not alter vasopressin binding or the stimulation of adenylate cyclase activity was also demonstrated (3). Here, we report the presence of a new polymorphism in 7 healthy Brazilian individuals, as well as in two unrelated patients with nephrogenic diabetes insipidus.

High molecular DNA was isolated from peripheral blood leukocytes according to a standard protocol (4). Based on the genomic sequence of the V2(R) gene (5), sense (5'CAT CCT GAA CCC AAC CTA C-3') and antisense (5'-CTC TAG AGG CAA GAC ACC C-3') primers were used, as previously described (6). The polymerase chain reac- 
Figure 1 - Direct sequence analysis of the amplified genomic fragment of exon 3 of the $V 2(R)$ gene showing a polymorphism* (AGT; right panel) as well as the published sequence (AGC; left panel) of codon 331.

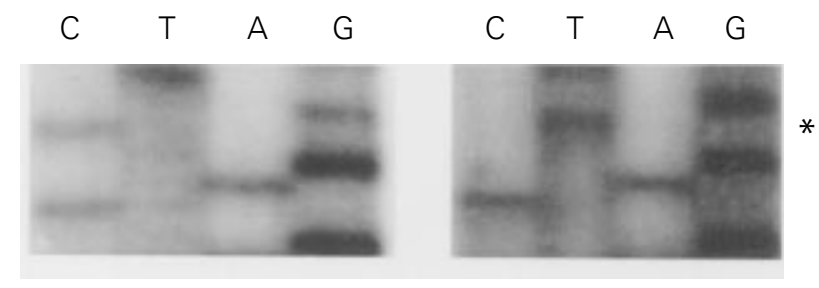

tion (PCR) was used to amplify this 270-bp fragment, encompassing the second intronic region and the 3' untranslated region. PCR conditions were as previously described (6). The amplified fragments were visualized by silver staining after electrophoresis on 5\% polyacrylamide gel to ascertain the correct size. For direct sequencing of PCR products, the Sequenase PCR Product Sequencing kit (United States Biochemical, Cleveland, $\mathrm{OH}$ ) was used, according to manufacturer instructions.

The data in Figure 1 show the presence of a $\mathrm{C} \rightarrow \mathrm{T}$ alteration in the third base of codon 331 for serine (AGC $\rightarrow$ AGT). This homozygous alteration was found in $25 \%(5 / 20)$ of all individuals, including two of the three individuals with nephrogenic diabetes insipidus, thus representing a polymorphism. Four individuals were heterozygous (AGC/ AGT). This alteration did not introduce or abolish any restriction site.

To date, 67 mutations have been described in unrelated nephrogenic diabetes insipidus families throughout the world $(7,8)$. However, no significant correlation of phenotype expression with genotypic variation has been demonstrated. The point mutation (A61V) that resulted in the substitution of one hydrophobic amino acid within the transmembrane region (3) was a rare polymorphism and did not cause the disease in that patient.
Therefore, possible structural variations in the sequence of a normal V2(R) gene are not accounted for in all cases of nephrogenic diabetes insipidus. Indeed, another gene, the vasopressin-regulated water channel aquaporin-2 gene, has been associated with the development of autosomal nephrogenic diabetes insipidus $(9,10)$. The identification of a second gene involved in the development of nephrogenic diabetes insipidus clearly indicates that linkage analysis should be performed before initiating mutation analysis to define which gene should be analyzed. Despite the similar clinical phenotype of all cases of nephrogenic diabetes insipidus, the analysis of several mutations reported here and the previously described polymorphisms has not shown the presence of a hot spot for these alterations, although most mutations are located in the transmembrane domain of the gene. Detection of polymorphic regions in the genes involved in the development of the disease may provide information about mutable areas within these genes.

In summary, we described here the third polymorphism in the vasopressin type 2 receptor gene, indicating that the possible structural variations in the sequence of this gene could be used, together with linkage analysis, to help understand the pathophysiology of the hereditary forms of nephrogenic diabetes insipidus. 


\section{References}

1. Pan $Y$, Metzenberg A, Das S, Jing B \& Gitschier J (1992). Mutations in the V2 vasopressin receptor gene are associated with X-linked nephrogenic diabetes insipidus. Nature Genetics, 2: 103-106.

2. Friedman $E$, Carson $E$, Larsson $C$ \& De Marco L (1993). A polymorphism in the coding region of the vasopressin type 2 (V2(R)) gene. Human Molecular Genetics, 2: 1746 .

3. Pan Y, Wilson P \& Gitschier J (1994). The effect of eight $V 2$ vasopressin receptor mutations on stimulation of adenylyl cyclase and binding to vasopressin. Journal of Biological Chemistry, 269: 3193331937.

4. Jeanpierre M (1987). A rapid method for the purification of DNA from blood. Nucleic Acids Research, 15: 9611.
5. Birnbaumer M, Seibold A, Gilbert S, Ishido M, Barberis C, Antaramian A, Brabet P \& Rosenthal W (1992). Molecular cloning of the receptor for human antidiuretic hormone. Nature, 357: 333-335.

6. Friedman E, Bale AE, Carson E, Boson W, Nordenskjöld M, Ritzén M, Ferreira PC, Jammal AR \& De Marco L (1994). Nephrogenic diabetes insipidus: an $X$ chromosome-linked dominant inheritance pattern with a vasopressin type 2 receptor gene that is structurally normal. Proceedings of the National Academy of Sciences, USA, 91: 8457-8461.

7. Bichet DG, Birnbaumer $M$, Lonergan $M$, Arthus M-F, Rosenthal W, Goodyear P, Nivet H, Benoit S, Giampietro P, Simonetti S, Fish A, Whitley CB, Jaeger P, Gertner J, New M, DiBona FJ, Kaplan BS, Robertson G, Hendy GN, Fujiwara TM \& Morgan K (1994). Nature and recurrence of AVPR2 mutations in X-linked nephrogenic diabetes insipidus. American Journal of Human Genetics, 55: 278-286.
8. Bichet DG (1996). Vasopressin receptors in health and disease. Kidney International, 49: 1706-1711.

9. Kanno K, Sasaki S, Hirata Y, Ishikawa S-E, Fushimi K, Nakanishi S, Bichet DG \& Marumo F (1995). Urinary excretion of aquaporin-2 in patients with diabetes insipidus. New England Journal of Medicine, 332: 1540-1545.

10. Deen PM, Verdijk MA, Knoers NV, Wieringa B, Monnens LA, van $\mathrm{Os} \mathrm{CH}$ \& van Oost BA (1994). Requirement of human renal water channel aquaporin-2 for vasopressin-dependent concentration of urine. Science, 264: 92-95. 